\title{
ANALYSING EXPERIENCED ORGANIC CHEMISTRY TEACHERS' TEACHING PLANS AND TASK PERFORMANCES BASED ON THE THEORY OF CONCEPTUAL FIELDS
}

\author{
Marcelo G. Nascimento, Marco Antonio Bueno Filho \\ Federal University of ABC (CCNH), Santo André, Brazil \\ E-mail: marcelo.gouveia@ufabc.edu.br, marco.antonio@ufabc.edu.br
}

\begin{abstract}
This research analyses two experienced Organic Chemistry teachers' teaching plans and task performances. The recorded audiovisual interviews were analyzed with computer assisted qualitative data analysis software (CAQDAS). Based on the Theory of Conceptual Fields, the teachers used an energetic-structural resolution approach characterized by the simultaneous use of structural field (SCF) and thermodynamics (TCF) articulated electronegativity, polar covalent bond, steric effects, inductive effects, resonance, aromaticity and stereochemistry. The development of the lesson plans indicated more emphasis to the structural field (SCF). The performance schemes of Organic Chemistry Tasks were not reflected into the lesson plans. Lesson planning knowledge that is subtly dependent on a teacher's career often has an implicit impact on the mobilization of the schemes.
\end{abstract}

Key words: Theory of Conceptual Fields, organic chemistry teachers, teaching planning.

\section{Introduction}

The domain of chemical concepts combined with the use of symbolic representation for undergraduates and prospective teachers is an instrumental factor to performing tasks that involve the proposition of chemical reaction mechanisms. Such tasks are described in the literature as a challenge to the learning process and to the proposition of teaching strategies capable of dealing with conceptual difficulties (Baker, George \& Harding, 1998; Paulton, 1999; Lipkowitz, Naylor \& Anliker, 2000; Bond-Robinson, 2005; Gravert, 2006; Mullins, 2008; Jones, Grahan \& Schaller, 2012; Albert, Todl \& Davis, 2012; Lafarge, Morge \& Méheut, 2014). Several authors have investigated the construction of Pedagogical Content Knowledge (PCK), a specific professional knowledge that characterizes the teaching action (Shulman, 1986, 1987; Grossman, 1994; Magnusson, Krajick, Borko, 1999; Gess-Newsome, 1999; De Jong, Van Driel \& Verloop, 2005; Kaya, 2009; Nilsson, 2009; Calik \& Aytar, 2013). PCK can be described as a fusion of pedagogical (PK) and subject matter knowledge (SMK) needed to transform a specific topic into teachable content (Shulman, 1986). Talanquer (2004) and Ekiz (2006) points out that prospective teachers have pitfalls linking their theoretical knowledge with practical one or balancing what is known with actions during applied courses. Just as the knowledge of many students to complete a course is characterized by a set of disconnected ideas and concepts, the PCK, a lot of teachers have little coherence and lack a solid foundation to stand on. Integration does not happen naturally and requires a level of reflection that teachers are not prepared or do not have time to develop it (Talanquer, 2004). Karakas (2013) reports that personal characteristics of graduate teachers affect the prospective teaching practices. In this scenario, it is legit the pursuit of information concerning how experienced teachers perform tasks and how they develop lesson plans. 
Marcelo G. NASCIMENTO, Marco Antonio BUENO FILHO. Analysing experienced organic chemistry teachers' teaching plans and task performances based on the theory of conceptual fields

OF EDU

PROBLEMS

IN THE $21^{\text {st }}$ CENTURY Volume 67,2015

Developing a lesson plan can be understood as a task in which concepts and operations of thinking are necessary. In view of Vergnaud (2009), while performing any kind of task, only part of the knowledge involved is explicit. Indeed, an important part of the knowledge remains implicit. Based on these assumptions, the objective of this study is to investigate how college organic chemistry teachers perform tasks, and what is the relation between a developed lesson plan and performance task for the same topic. In other words, taking into account that part of the knowledge is implicit, which knowledge area is used during task performing and which is arisen during the development of lesson plans to teach the very same topics?

According to the Theory of Conceptual Fields (Vergnaud, 1990, 2009), both the resolution of Organic Chemistry formal tasks and the development of lesson plans can be understood as situations that are object of knowledge that require a cognitive action in both conceptual and symbolic fields. The way each subject organizes concepts, symbolic representations and general thinking operations are designated as schemes.

The scheme concept is supported by the works of Jean Piaget (1975), initially associated to the actions of children in the sensory-motor stage. According to this author, the schemes used by the human being are considered fundamental elements to the knowledge building.

The schemes are supposed to be connected to the forms of organization of both the sensory-motor and intellectual skills. However, the practical schemes demanded during the sensory-motor stage did not maintain an evident conceptual content. Vergnaud (1996) also uses the concept of scheme, but connected to the conceptual contents of thinking, particularly those related to the resolution of school tasks. The schemes are accessible to the subject, acting as effective organizers of thinking (Vergnaud, 1998). They are ways of conduct that, full of conceptual content, characterize the actions of a subject when facing a group of situations, operating as the main organizer of human thinking.

Consequently, the nucleus of cognitive development is conceptualization (Vergnaud, 1990). In the Theory of Conceptual Fields, the formation of a concept is associated to the triad (Situations (S) that give meaning to the concepts, invariants (I) that is responsible for the conceptual content and the operability of schemes, Representation (R) which is the component connected to the verbal and non-verbal forms, which allow for a symbolic representation of the concept, its properties and treatment procedures) (Moreira, 2002).

Based on these considerations, the following hypothesis have been made about experienced teacher's subject matter knowledge (SMK):

H1: The schemes mobilized during the resolution of Organic Chemistry situations are not dependent on the question wording or the way the questions are presented. They depend on the concept fields mobilized by the questions.

$\mathrm{H} 2$ : The resolution of Organic Chemistry situations requires the use of schemes that are accessible to the subjects, but the implicit nature of part of the contents has a qualitative impact on the schemes involved in performing and planning tasks.

H3: The schemes involved in the resolution of Organic Chemistry situations are not conveyed to the action of planning the teaching of the same topic. Teaching planning requires knowledge that is subtly developed during a teacher's career. This knowledge, often implicit, has an impact on the mobilization of the schemes.

\section{Methodology of Research}

\section{General Background of Research}

The results of this research were obtained from interviews with teachers of Organic Chemistry in a Brazilian public university. A qualitative evaluation was carried out seeking the 
Marcelo G. NASCIMENTO, Marco Antonio BUENO FILHO. Analysing experienced organic chemistry teachers' teaching plans and task performances based on the theory of conceptual fields

interviews for the implicit and explicit conceptual contents related to task performing in the structural field, and the teaching planning of the same topic.

\section{Participants and Setting}

Two teachers of the Federal University of ABC participated in the study, both of which hold a PhD in Organic Chemistry and frequently teach subjects within this area of knowledge. A description of the participating teachers is briefly presented in Table 1:

Table 1. General characterization of the investigated teachers ( $T$ ).

\begin{tabular}{|c|c|c|}
\hline Experience as a college teacher & Education & Frequently taught subjects \\
\hline 2009 - present & $\begin{array}{l}\text { Bachelors in Chemistry (1995-2000) } \\
\text { PhD in Organic Chemistry (2000- } \\
2005) \\
\text { Postdoctoral (2005-2008) }\end{array}$ & $\begin{array}{l}\text { Advanced Organic Chemistry I } \\
\text { Mechanisms of Chemical and Bio- } \\
\text { chemical Reactions } \\
\text { Advanced Organic Chemistry II } \\
\text { Chemical Transformations } \\
\text { Biochemical Transformations } \\
\text { Organic Functions and Reactions } \\
\text { Applied Organic Chemistry } \\
\text { Mechanisms of Organic Reactions }\end{array}$ \\
\hline T2 2009 - present & $\begin{array}{l}\text { Bachelors in Chemistry (1992-2002) } \\
\text { Masters in Organic Chemistry (2003- } \\
\text { 2005) PhD in Organic Chemistry } \\
(2005-2009)\end{array}$ & $\begin{array}{l}\text { Advanced Organic Chemistry I } \\
\text { Integrated Chemistry I } \\
\text { Integrated Chemistry II } \\
\text { Chemical Transformations } \\
\text { Organic Functions and Reactions } \\
\text { Applied Organic Chemistry } \\
\text { Mechanisms of Organic Reactions }\end{array}$ \\
\hline
\end{tabular}

\section{Instrument and Procedures}

The study was based on the analysis of the explanations proposed by the teachers for two similar conceptual tasks that involved the mechanisms of organic reactions. The conceptual core of such tasks involved the formation of an intermediary carbocation via a first-order nucleophilic substitution $\left(\mathrm{S}_{\mathrm{N}} 1\right)$. Figures 1 and 2 show the wording of tasks $\mathrm{S} 1$ and $\mathrm{S} 2$ :

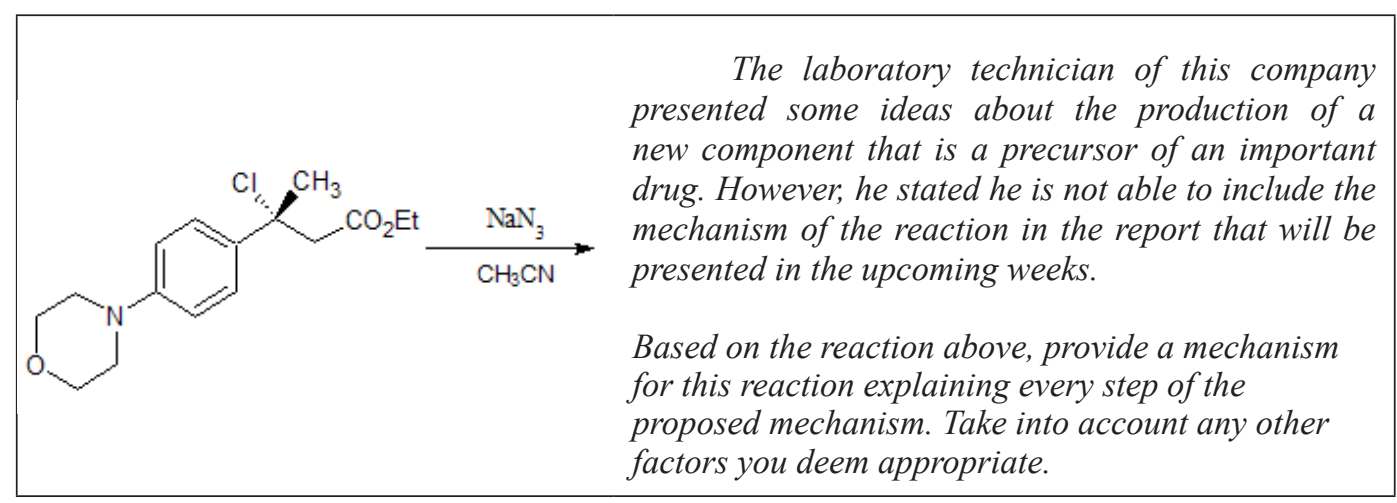

Figure 1: Organic chemistry task S1. 
Marcelo G. NASCIMENTO, Marco Antonio BUENO FILHO. Analysing experienced organic chemistry teachers' teaching plans and task performances based on the theory of conceptual fields

BLEMS

OF EDUCATION

IN THE $21^{\text {st }}$ CENTURY

Volume 67, 2015
Based on the reaction above, provide a mechanism for this reaction explaining every step of the proposed mechanism. Take into account any other factors you deem appropriate.<smiles>CC[C@H](Br)c1ccccc1</smiles>

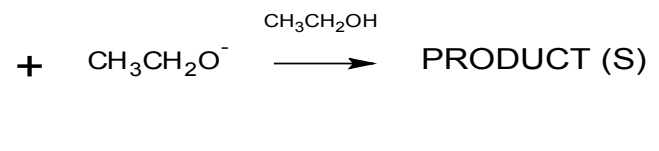

Scenario

\section{Proposition}

Reaction via $S_{N} 1$ forming an enantiomeric pair.

Reaction via $S_{N} 2$ forming only one product and $100 \%$ yield.

Competition between $S_{N} 2$ and E1 reactions

Competition between $S_{N} 1$ and $E 1$ reactions.

Competition between $S_{N} 1$ and $E 1$ reactions.

\section{Figure 2: Organic chemistry task S2.}

The task S2 comprised five scenarios with different reaction outcomes. The teacher should choose one scenario based on the mechanism of the reaction. Scenario 4 was the most appropriate one, because it comprised the competition between the elimination and substitution reactions, both of first-order. Table 2 presents which tasks were presented to each one of the teachers, and the questions asked on the semi-structured interview sessions during the resolution of the task and proposition of the teaching plans.

\section{Table 2. Questions of the semi-structured interviews.}

\begin{tabular}{|c|c|c|c|}
\hline Teacher & Task & Resolution & Teaching Planning \\
\hline \multirow[t]{2}{*}{$\mathrm{T} 1$} & \multirow[t]{2}{*}{$\mathrm{S} 1$} & $\begin{array}{l}\text { 1. Perform this task presenting the } \\
\text { reaction mechanism. }\end{array}$ & $\begin{array}{l}\text { 1. Which concepts/content are important to teach } \\
\text { students how to solve this kind of chemical trans- } \\
\text { formation question? }\end{array}$ \\
\hline & & $\begin{array}{l}\text { 2. Which are the most important steps } \\
\text { to the resolution of this task? }\end{array}$ & $\begin{array}{l}\text { 2. In your opinion, which factors should be taken } \\
\text { into account when developing a lesson plan to } \\
\text { teach this kind of reaction? }\end{array}$ \\
\hline \multirow{3}{*}{$\mathrm{T} 2$} & \multirow{3}{*}{ S2 } & $\begin{array}{l}\text { 3. Which factors are important to the } \\
\text { proposition of this mechanism? }\end{array}$ & $\begin{array}{l}\text { 3. Develop a lesson plan ( } 1 \text { or more classes) to } \\
\text { teach the topics involved in this reaction. }\end{array}$ \\
\hline & & $\begin{array}{l}\text { 4. Detail the data you considered in } \\
\text { order to propose a mechanism. }\end{array}$ & $\begin{array}{l}\text { 4. What difficulty level would you attribute to this } \\
\text { question? }\end{array}$ \\
\hline & & $\begin{array}{l}\text { 5. Is there any other relevant informa- } \\
\text { tion you would like to mention? }\end{array}$ & $\begin{array}{l}\text { 5. What is the most important information to be } \\
\text { presented in class to ensure the concepts of this } \\
\text { task are understood. }\end{array}$ \\
\hline
\end{tabular}

The tasks were presented to the teachers and they were asked to present their method of resolution orally. The use of the board to write the symbolic representations that were necessary to perform each of the situations was allowed. The semi-structured interview was performed during the oral explanation. The objective was to identify the conceptual contents and the operative invariants in the explanations. The explanations were recorded on an audiovisual device, transcribed and analyzed. 
Marcelo G. NASCIMENTO, Marco Antonio BUENO FILHO. Analysing experienced organic chemistry teachers' teaching plans and task performances based on the theory of conceptual fields

\section{Data Analysis}

The content of the oral explanations, including the gestures performed by the teachers, were transcribed and subjected to Discourse Analysis (Galiazzi \& Moraes, 2006) via CAQDAS, Computer-Assisted Qualitative Data Analysis Software supported by the Transana Software (Winconsin Center for Educational Research [WCER], 2011). The Discourse Analysis presumes the fragmentation of text into manageable sub-groups called unities of meaning. In order to attribute meaning to the textual units, the criteria below were organized in dimensions (Table $3)$.

\section{Table 3. Dimensions used in data analysis.}

\begin{tabular}{|l|l|l|}
\hline Dimension & Definition & Attributions \\
\hline D1 - Conceptual & $\begin{array}{l}\text { Arise from the resolution of tasks and connect } \\
\text { to the operative invariants and symbolic repre- } \\
\text { sentations related to the structural field. }\end{array}$ & $\begin{array}{l}\text { Electronegativity, Polar covalent bond, } \\
\text { Steric effects, Inductive effects, Reso- } \\
\text { nance, Aromaticity, Stereochemistry } \\
\text { (Mullins, 2008; Nascimento \& Bueno Filho, } \\
\text { 2013) }\end{array}$ \\
\hline $\begin{array}{l}\text { D2 - Operative } \\
\text { Invariants }\end{array}$ & $\begin{array}{l}\text { Theorems and implicit or explicit ideas used } \\
\text { during the teachers actions and often charac- } \\
\text { terized by general logic operations of thinking. }\end{array}$ & $\begin{array}{l}\text { Considering possibilities, making } \\
\text { comparisons, describing hypothesis, free } \\
\text { molecular movement, molecular orienta- } \\
\text { tion, simultaneity. }\end{array}$ \\
\hline $\begin{array}{l}\text { D3 - Structure of the } \\
\text { Explanations }\end{array}$ & $\begin{array}{l}\text { Structure that characterizes the student's } \\
\text { sequence of actions. Comprises the develop- } \\
\text { ment of justifications and inferences. }\end{array}$ & $\begin{array}{l}\text { Justifications and Inferences } \\
\text { D4 - Gestures }\end{array}$ \\
$\begin{array}{l}\text { Movements containing meaning performed } \\
\text { by the acting subjects. Directly related to the } \\
\text { concepts and operative invariants implicit in } \\
\text { the actions. }\end{array}$ & $\begin{array}{l}\text { Cohesive, demonstratives, iconic, beats, } \\
\text { metaphoric (McNeill, 1992) }\end{array}$ \\
\hline
\end{tabular}

\section{Results of Research}

\section{Structural Conceptual Field and Thermodynamic Conceptual Field}

While performing tasks S1 and S2, the teachers developed proposals of mechanisms based on Organic Chemistry knowledge. Even though the tasks had different wording, their resolution required the same group of concepts. In both cases the teachers proposed first-order nucleophilic substitutions $\left(\mathrm{S}_{\mathrm{N}} 1\right.$ mechanism) initiated by the break of the polar carbon-halogen bond with simultaneous formation of an intermediary carbocation stabilized by resonance via aromatic group. The influence of the solvent on the stability of the reaction intermediary was also considered by the teachers as an additional factor to justify the unimolecular mechanism. Additionally, due to the formation of the carbocation intermediary, the possibility of a unimolecular elimination ( $\mathrm{E}_{1}$ mechanism) happening concurrently with the substitution reaction was considered.

The concepts used by the teachers were related to aspects that linked the nature and proprieties of chemical bonds to the reactivity, for example, the relation between the polarization of bonds and leaving groups, or the addition of nucleophilic species to electrophiles as groups containing opposite charge. Explanations that link chemical concepts in that fashion characterize the Structural Conceptual Field (SCF). A second field arose from the allusions about the energetic stability of the system, supported by justifications that considered solvation effects 
Marcelo G. NASCIMENTO, Marco Antonio BUENO FILHO. Analysing experienced organic chemistry teachers' teaching plans and task performances based on the theory of conceptual fields

PROBLEMS

OF EDUCATION

IN THE $21^{\text {st }}$ CENTURY

Volume 67,2015

or stabilization by resonance of the reaction intermediary, called Thermodynamic Conceptual Field (TCF).

Table 4 presents the first-order mechanisms proposed in both cases and the main concepts and fields used by the teachers.

Table 4. Reaction mechanisms of each task, concepts and conceptual fields involved.

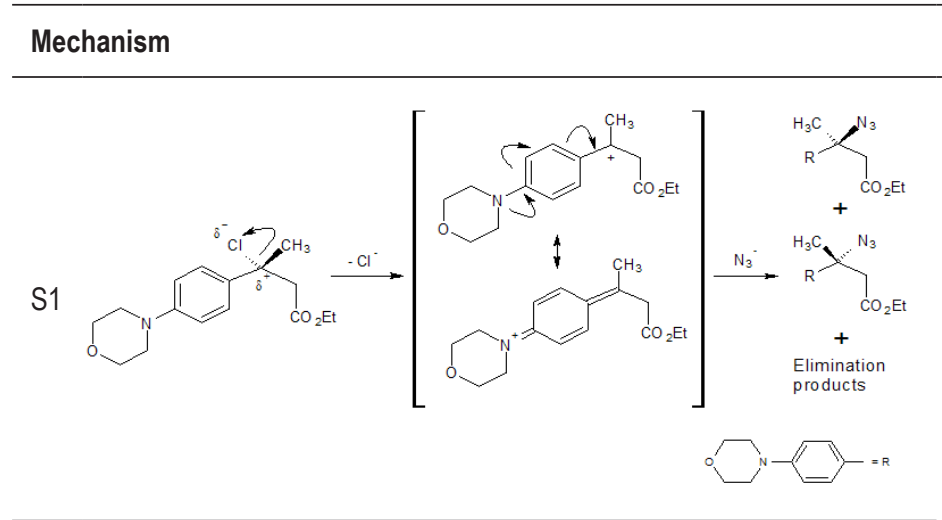

Conceptual Fields involved

Structural Conceptual Field Discusses the possibility of formation of carbocation (intermediate reaction).

The explanations for the most part are of a structural nature in terms of reagents and products.

Alludes structural issues solvent and molecular analysis based on structural concepts of organic chemistry Mullins, 2008).

Presents significant importance breaks chemical bonds.

\section{Thermodynamic Conceptual Field}

Discusses the possibility of formation of carbocation (intermediate reaction).

In many shifts refers to the energy factors as carbocation stability, solvent effect on the intermediate analysis of the reaction medium, EZ isomerism and stability. Justify on structural characteristic of stereoisomers, chirality and chiral inversion center, racemic mixture, the influence of Lewis acids and bases and polarity structures. Alludes to the energetic factors: stabilization through resonance and the role of the solvent effect, the forward reaction intermediate.

\section{Discussion}

The Structural Conceptual Field and Thermodynamic Conceptual Field used together characterized the teachers's subject matter knowledge (SMK). Six core concepts in Organic 
Marcelo G. NASCIMENTO, Marco Antonio BUENO FILHO. Analysing experienced organic chemistry teachers' teaching plans and task performances based on the theory of conceptual fields

Chemistry were used as linking concepts of the SCF and TCF fields during the resolution of the situations. The concepts are electronegativity, polar covalent bond, steric effects, inductive effects, resonance, aromaticity proposed by Mullins (2008) in addition to stereochemistry (Nascimento \& Bueno Filho, 2013). This is shown in Figure 3.

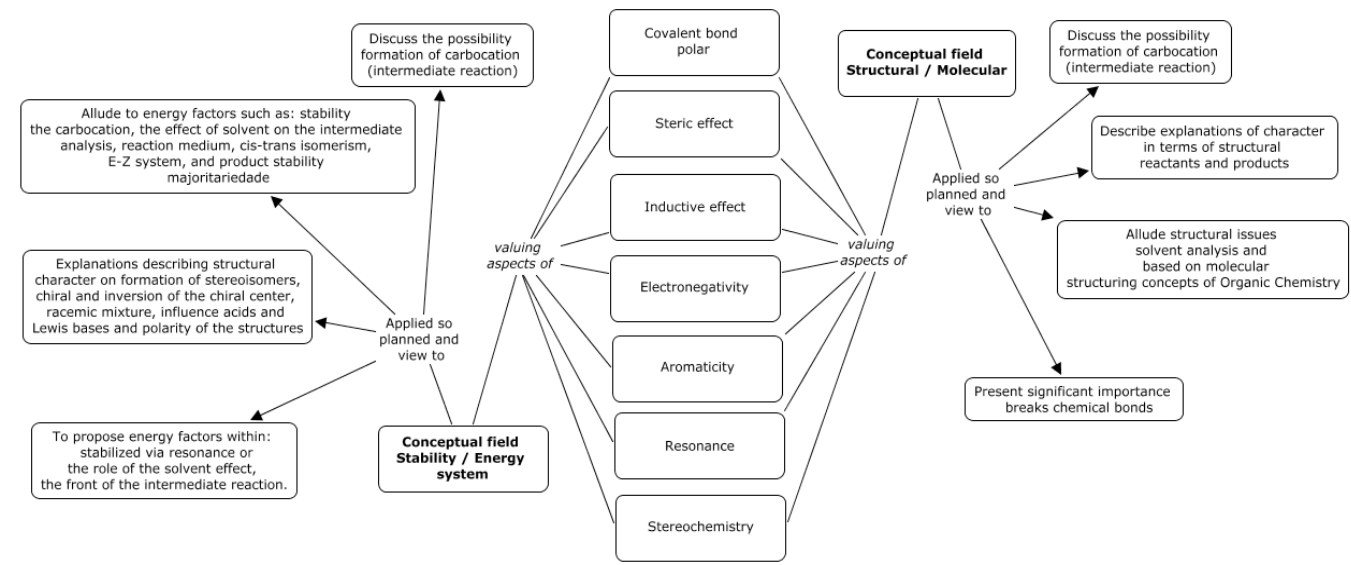

Figure 3: Articulation of conceptual fields via structuring concepts

\section{Schemes involved when performing tasks}

Teacher $\mathrm{T} 1$ often used justifications that emphasized the stability of the reaction intermediary and the system energy (carbocation stabilization via resonance or solvation by solvent effect), as well as factors of structural nature (polarization of bonds or inductive effects), as the strategy to explain the mechanism of nucleophilic substitution:

T1: Polar aprotic solvent solvates cations, but not anions. In this case, there is a disadvantage to the $\mathrm{S}_{\mathrm{N}} 1$ process $(0: 03: 47.4)$. $(0: 03: 54.7)$.

T1: It is possible to solvate to favor the break of the bond between carbon and chloride

T1: However, breaking the carbon chloride bond forms a tertiary benzylic carbocation (0:04:44.8).

T1: What is the advantage of the benzylic carbocation? It is quite simple! Due to the stabilization of the aromatic pi system with the methyl and the rest of the molecule, there is a reaction between the $p$ orbital of the carbocation with the benzylic system $(0: 05: 53.8)$.

Figure 4 contains the temporal overlap of concepts and operative invariants involved in the resolution of task S1 that characterize the scheme used by teacher T1, as well as the conceptual fields SCF and TCF:

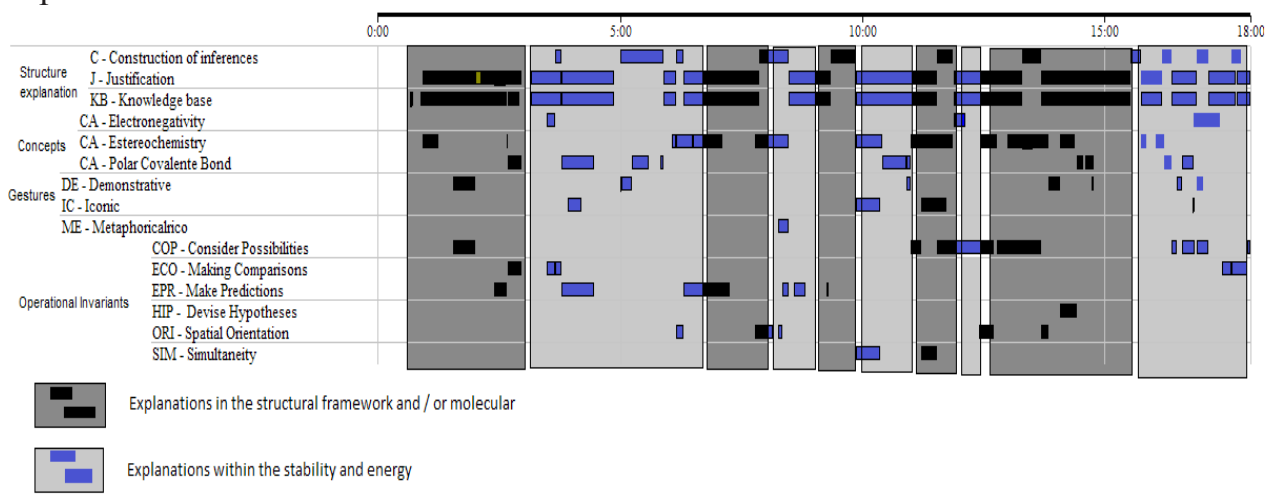

Figure 4: Contents of the Scheme used by teacher T1 during the resolution of task S1. 
Marcelo G. NASCIMENTO, Marco Antonio BUENO FILHO. Analysing experienced organic chemistry teachers' teaching plans and task performances based on the theory of conceptual fields

OF EDUCA

IN THE $21^{\text {st }}$ CENTURY Volume 67,2015

Based on the diagram, it was noticed that the explanation was characterized by concepts that supported justifications followed by the drawing of inferences. Additionally, the concepts and justifications were frequently aligned with the operative invariants. The pertinent association of elements of conceptual and logical-formal nature (operative invariants) with the justifications in the schemed adopted by the teacher provided the operability necessary to the resolution of the task. Besides, there was a rotation in the use of different conceptual fields (SCF and TCF).

Faced with situation S2, conceptually similar, the explanation of the Teacher T2 presented characteristics similar to $\mathrm{T} 1$ :

T2: In the present case, there is some reaction product originated from a $\mathrm{S}_{\mathrm{N}} 2$ reaction. It is important to notice there was inversion of the chiral center. The hydrogen that was behind the reagent molecule come to the front. (0:08:54.7)

T2: It is likely that a solvent with high dielectric constant will end up solvating the carbocation, and in this context, there is a mixture of $\mathrm{S}_{\mathrm{N}} 1$ products. In addition, it is likely that there is a racemic mixture in this reaction, between these two chiral products. The reaction medium also favors elimination reactions $(0: 13: 43.5)$.

T2: The reaction presents a mixture of isomers. They are spatial isomers and diastereoisomers. Mostly, there will be a product of $\mathrm{E}$ character that contributes to the decrease in the system energy $(0: 14: 51.2)$.

Figure 5 contains the temporal overlap of concepts and operative invariants involved in the resolution of task $\mathrm{S} 2$ that characterize the scheme used by teacher $\mathrm{T} 2$.

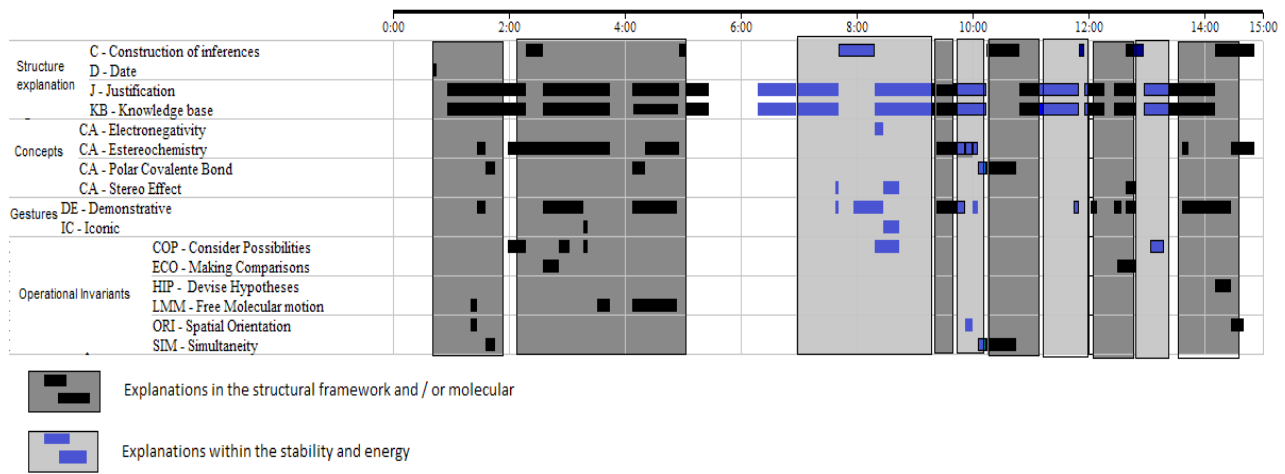

\section{Figure 5: Contents of the Scheme used by teacher T2 during the resolution of task S2.}

The strategy used by teacher $\mathrm{T} 2$ considered the competition between the mechanisms $\mathrm{S}_{\mathrm{N}} 1$ vs $\mathrm{S}_{\mathrm{N}} 2$ since there was a secondary organic halide. Based on this scenario, he proposed the occurrence of reaction products characterized by the inversion of the stereogenic center (via $\mathrm{S}_{\mathrm{N}} 2$ mechanism) in addition to those resulting from the unimolecular mechanism $\left(\mathrm{S}_{\mathrm{N}} 1\right)$. Another recurrent conceptual connection was the association of the solvent dielectric constant with the stabilization by solvation of the carbocation intermediary. The idea of energetic stability was also considered to explain the main formation of the stereoisomer of $\mathrm{E}$ configuration originated from elimination via unimolecular elimination mechanism, E1.

Even though S1 and S2 involved different substrates (S1, tertiary organic halide and S2, secondary organic halide) the teachers used schemes characterized by similar contents. The analysis of Figures 4 and 5 show the rotation of concepts linked to the Structural Conceptual Field (SCF) and Thermodynamics Conceptual Field (TCF), called Energetic-Structural Scheme. The main characteristic of this scheme is the successive and conceptually interconnected use of conceptual fields related to structural and thermodynamic aspects of chemical transformations. 
Marcelo G. NASCIMENTO, Marco Antonio BUENO FILHO. Analysing experienced organic chemistry teachers' teaching plans and task performances based on the theory of conceptual fields

It is worth mentioning the role and place occupied by the operative invariants in the schemes used by the teachers - the formulation of hypothesis about the model, the spatial orientation, that is, realizing the possibilities in a tridimensional universe, and the free molecular movement constituted formal operations of thinking frequently aligned with the ideas polarity, breaking and formation of new chemical bonds associated with the Structural Conceptual Field (SCF). The operations of thinking linked to the simultaneity of events associated with stereochemistry (concomitant presence of two stereoisomers, for example) were connected to the Thermodynamic Conceptual Field (TCF). The mobilization of the SCF comprehends the reference to:

a. Possibility of formation of a reaction intermediary;

b. Analysis of structural factors of reagents and products;

c. Break and formation of chemical bonds, relating molecular geometry, polarities and interactions between chemical species.

The mobilization of the TCF comprehends the reference to factors that contribute to system energy minimization such as:

a. Stabilization of reaction intermediaries via polar interactions with solvent molecules;

b. Stabilization of reaction intermediaries via resonance effects inherent to the structure of the organic substrate;

c. Stabilization of reaction intermediaries due to inductive effects or mesomeric effects caused by polar groups;

d. Occasional predominance of stereoisomers taking into account steric effects (typically in the case of diastereoisomers);

\section{The place of SCF and TCF fields in the proposition of Lesson Plans}

During the step of elaboration of a lesson plan about situations S1 and S2, a predominance of SCF over TCF was observed as shown in Table 5. The teacher valued: the importance of substrate structure; intermolecular interactions; kinetic aspects of chemical transformations; importance of proper understanding of Lewis structures; Valence-Shell Electronic Pair Repulsion Theory (VSEPR) combined with steric factors; electronegativity difference between the atoms; bases force (Acid-Base Theories). However, ideas related to the energetic stabilization of the system via TCF were not very emphasized in the lesson plan, being reported only the solvent effect on the stabilization of the reaction intermediary by solvolysis and the importance of bond enthalpies.

Nevertheless, it is necessary to consider that the action of developing a lesson plan is not the same kind of situation as the resolution of a simple task by a specialist. Developing a lesson plan requires the setting of educational goals, priorities and escalation of contents, taking into consideration that such contents shall be taught. In other words, it is expected that the schemes involved during the development of a lesson plan consider the pedagogic repertoire built by the teachers along their careers.

Even affected by the pedagogic repertoire, it calls attention the fact that only one of the teachers mentioned Physical Chemistry knowledge as being important to understand mechanist propositions in Organic Chemistry, yet mentioning the kinetic of chemical transformations instead of thermodynamic.

This teacher claimed energetic aspects are secondary tools to the teaching of the presented reaction, or are only important in isolated cases. It is noteworthy that this teacher considered energetic stabilization in several moments when doing the task (S1). Figure 6 shows 
Marcelo G. NASCIMENTO, Marco Antonio BUENO FILHO. Analysing experienced organic chemistry teachers' teaching plans and task performances based on the theory of conceptual fields

PROBLEMS

OF EDUCATION

IN THE $21^{\text {st }}$ CENTURY

Volume 67,2015

a schematic proposal of how the SCF and TCF fields are mobilized during the resolution of tasks and teaching planning.

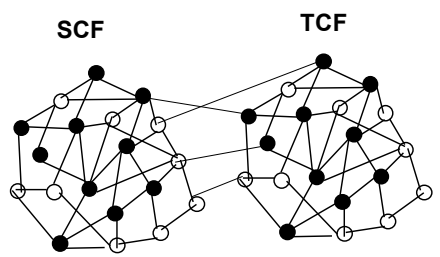

Organic Chemistry Tasks

OOrganic Chemistry Concepts

- Operative Invariants

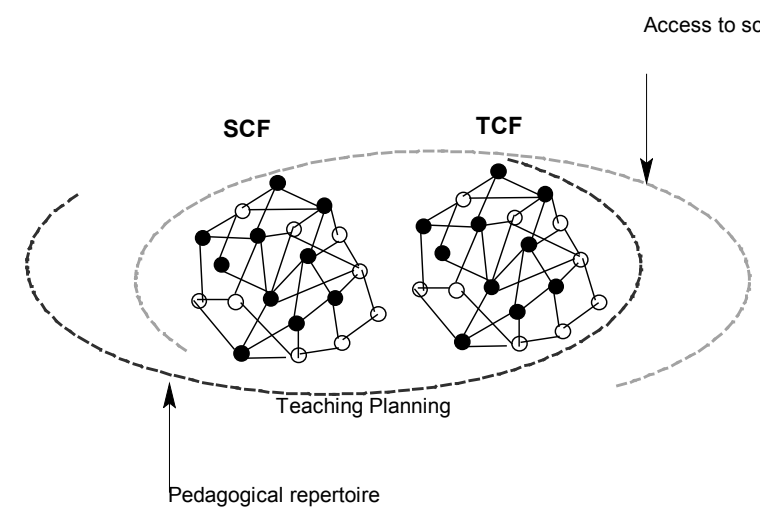

Figure 6: Integration of SCF and TCF on the resolution of a complex task and teaching planning. 


\section{Table 5: Location of contents related to SCF and TCF fields in teachers T1 and T2 lesson plans.}

Important concepts to teaching the chemical transformations involved in S1

(Total 3 classes)
SCF

Structure related concepts (stereochemistry).

Aliphatic nucleophilic substitution reactions $\left(S_{N} 2 / S_{N} 1\right)$.

Dependence of substrate structure and solvent effect (nucleophilicity, formation of carbocation/solvolysis, molecular interactions, reaction speed.

Class 1: Aliphatic nucleophilic substitution; Transition state; Kinetic; Mechanism (Steps 1 and 2).

Classes 2 and $3: \mathrm{S}_{\mathrm{N}} 2$ / $\mathrm{S}_{\mathrm{N}} 1$; Structure effect; Solvent effect (protic/aprotic); Molecular interactions; Stereochemistry in $\mathrm{S}_{\mathrm{N}} 2$ and $\mathrm{S}_{\mathrm{N}} 1$; Competition $\mathrm{S}_{\mathrm{N}} 2 \times \mathrm{S}_{\mathrm{N}} 1$; Exercises; Discussion of cases.
TCF

Energetic (carbocation stability) associated with the electronic effect of the replacement group in the aromatic ring on the reactivity of benzyl chloride

Differentiation between $\mathrm{S}_{\mathrm{N}} 2$ and $\mathrm{S}_{\mathrm{N}} 1$ and discussion of

Other relevant ideas to the development of substrate conditions, nucleophile and solvent that favor S1 lesson plan each process.

Structure of organic compounds (Lewis structure), and spatial geometry (VSPER and isomerism)

Steric impediment, electronegativity difference, strength of chemical bonds, bases force

Important concepts to teaching the chemical transformations involved in S2 (Total 4 classes)

Afterwards start the reaction mechanisms topic and analyze the competition between addition and elimination reactions.

Class 1: Lewis Structure; VSPER; C-heteroatom bond strength; Isomerism.

Class 2: Bronsted Acid-Base; Lewis Acid-Base.

Class 3: Addition Reactions; Elimination Reactions.

Class 4: Particularities of the reactions.

Other relevant ideas

Understanding the structure of the molecules involved in

to the development of

S2 lesson plan the reaction instead of simply presenting the details and particularities of the mechanisms related to the chemical transformation.

\section{Dialogue with the teachers}

Researcher: How does the energetic issue comes into the lesson plan for this reaction? Is it possible to find support in thermodynamic to explain the structural and molecular aspects in this situation?

T1: Undoubtedly, the most important Physical Chemistry concept related to this topic is kinetics. In a traditional approach of this case, the thermodynamic is not particularly considered. This is different when we are talking about the stability of arenos. In that case, you present thermodynamic and stability parameters in order to justify the lower reactivity of the aromatic system.

T1: In order to justify the carbocation stability, we usually present the structural factors that allow the stabilization of that empty $p$ orbital of the carbocation with six electrons that are generally electronic effects of the groups surrounding carbons lacking electrons. However, if you consider thermodynamic of stability, it is subtle in the matter of how easily the reaction occurs.

Researcher: It seems the main aspect of your lesson plan is teaching concepts in the structural sphere. Is it accurate? T1: Yes! However, the kinetic description of the processes is well defined. Moreover, the most important thing is that when you discuss $\mathrm{S}_{N} 1$ and $\mathrm{S}_{N} 2$ reactions from a kinetic perspective, this is the first moment when you tell the student that the kinetic law allows you to state that the reaction occurs via bimolecular or unimolecular mechanism.

Researcher: Do you believe the connection between thermodynamic and structures/reactivity can occur in your lesson plan?

T2: I never rationally thought about whether or not it is important. In order to understand the mechanism, I believe it is not that important. The understanding of thermodynamic parameters is not vital to the understanding of the reaction mechanism 
Marcelo G. NASCIMENTO, Marco Antonio BUENO FILHO. Analysing experienced organic chemistry teachers' teaching plans and task performances based on the theory of conceptual fields

OF EDUCAT

IN THE $21^{\text {st }}$ CENTURY

Volume 67, 2015

\section{Conclusions}

In this research, two experienced Organic Chemistry teachers were evaluated. They performed two tasks that involved the mechanistic proposition of first-order nucleophilic substitution reactions. Even though the structure of the compounds was different, it was possible to notice similarities in the mobilized schemes. The schemes called energetic-structural were characterized by the simultaneous use of the structural field (SCF) and thermodynamic (TCF), articulated by core concepts in Organic Chemistry: electronegativity, polar covalent bond, steric effects, inductive effects, resonance, aromaticity Mullins (2008) and stereochemistry (Nascimento \& Bueno Filho, 2013). Formal operations of thinking were preferably aligned in these schemes. In particular, considering possibilities about a model, making comparisons and formulating hypothesis operated preferentially on structural concepts (SCF) and spatial orientation and simultaneity of events on concepts that guide the stability of the system (TCF). Thus, the schemes mobilized during the resolution of Organic Chemistry situations are not dependent on the question wording or the presentation of the questions. They depend on concept fields mobilized by the situations.

Although choosing a resolution mode (scheme) can be accessible to the subjects, the implicit nature of the content of the schemes has a qualitative impact on the schemes involved when performing tasks and planning tasks. Moreover, the schemes involved in the resolution of Organic Chemistry situations, the subject matter knowledge (SMK), are not completely conveyed to the action of planning the teaching of the same topic. Teaching planning requires knowledge that is subtly developed during a teacher's career, has an implicit impact on the mobilization of the schemes and should be taken into account.

Access to PCK components by Conceptual Fields Theory approach is still little explored in recent literature. Admitting that the mobilization of different concept fields, the SCF and TCF, characterizes the subject matter knowledge (SMK) about Organic Chemistry in experienced teachers can be useful to planning university teacher training courses with the following goals:

1. Understand curricula on Organic Chemistry in terms of Conceptual Fields - structural and thermodynamic fields;

2. Reflect on the cognitive demand required for solving tasks in this champs;

3. Confront and solve tasks and how they plan teaching.

Additionally, could be considered the reflection about teaching plans in relation to records of actions in the classroom. This step was not investigated in this work but could consist in a new study. University teacher training courses like this could contribute positively to the prospective teaching practice.

\section{Acknowledgements}

Acknowledgement to FAPESP (Fundação de Amparo à Pesquisa do Estado de São Paulo).

\section{References}

Albert, D. R., Todt, M. A. \& Davis, H. F. (2012). A low-cost quantitative absorption spectrophotometer. Journal of Chemical Education, 89, 1432-1435.

Baker, R. W., George, A.V., Harding, M. M. (1998). Models and molecules - a workshop on stereoisomers. Journal of Chemical Education, 75 (7), 853-855.

Bond-Robinson, J. (2005). Identifying pedagogical content knowledge (PCK) in the chemistry laboratory. Chemistry Education Research and Practice, 6 (2), 83-103. 
Marcelo G. NASCIMENTO, Marco Antonio BUENO FILHO. Analysing experienced organic chemistry teachers' teaching plans and task performances based on the theory of conceptual fields

Calik, M. \& Aytar, A. (2013). Investigating prospective primary teachers’ pedagogical content knowledge of "Effect of human on environment" subject in process of teaching practice. Educational Science: Theory and Practice, 13 (3), 1579-1605.

De Jong, O., Van Driel, J., \& Verloop, N. (2005). Preservice teachers' pedagogical content knowledge of using particle models when teaching chemistry. Journal of Research in Science Teaching, 42 (8), 947-964.

Ekiz, D. (2006). Kendini ve başkalarını izleme: Sınıf öğretmeni »duylarının yansıtıcı günlükleri. Illkögretim-Online, 5 (1), 45-57.

Galiazzi, M. C., \& Moraes, R. (2006). Análise textual discursiva: processo reconstrutivo de múltiplas faces. Ciência \& Educação, 12 (1), 117-128.

Gess-Newsome, J. (1999). Pedagogical content knowledge: an introduction and orientation. In: GessNewsome, J. \& Lederman, N.G. (Eds.). Examining Pedagogical Content Knowledge, Dordrecht, the Netherlands: Kluwer Academic Publishers.

Gravert, D. J. (2006). Active learning and cooperative learning in the organic chemistry lecture class. Journal of Chemical Education, 83 (6), 898-901.

Grossman, P. L. (1990). The making of a teacher: teacher knowledge and teacher education. New York: Teachers College Press.

Jones, T. N., Grahan, K. J., \& Schaller, C. P. (2012). A jigsaw classroom activity for learning IR analysis in organic chemistry. Journal of Chemical Education, 89, 1293-1294.

Kaya, O. N. (2009). The nature of relationships among the components of pedagogical content knowledge of pre-service science teachers: "Ozone layer depletion" as an example. International Journal of Science Education, 31 (7), 961-988.

Karakas, M. (2013). Prospective elementary teachers views on their teachers and their effectiveness. The Qualitative Report, 18 (86), 1-17.

Lafarge, D. L., Morge, L. M., \& Méheut, M.M. (2014). A new higher education curriculum in organic chemistry: What questions should be asked? Journal of Chemical Education, 91, 173-178

Lipkowitz, K., B., Naylor, T. \& Anliker K., S. (2000). Introducing chiroscience into the organic laboratory curriculum. Journal of Chemical Education, 77 (3), 305-307.

Magnusson, S., Krajick, J., Borko, H. (1999). Nature, sources, and development of pedagogical content knowledge for science teaching. In: Gess-Newsome, J., Lederman, N. G. (Org.), Examining pedagogical content knowledge: The construct and its implications for science education. Dordrecht: Kluwer Academic Publishers.

McNeill, D. (1992). Hand and mind: What gestures reveal about thought. Chicago: University of Chicago Press.

Mullins, J. J. (2008). Six pillars of organic chemistry. Journal of Chemical Education, 85 (1), 83-87.

Nascimento, M. G., \& Bueno Filho, M. A. (2013). Elementos estruturadores da Química Orgânica Implícitos na argumentação de professor e alunos de graduação. Enseñanza de las Ciencias, v. extra, 1629-1634.

Nilsson, P. (2009). From lesson plan to new comprehension: Exploring student teachers' pedagogical reasoning in learning about teaching. European Journal of Teacher Education, 32, 239-258.

Paulson, D. R. (1999). Active learning and cooperative learning in the organic chemistry lecture class. Journal of Chemical Education, 76 (8), 1136-1140.

Piaget, J. (1975). A relação entre sujeito e objeto. In: Carmichel, L. (Ed.), Manual de psicologia da criança. São Paulo: EPU.

Shulman, L. S. (1986). Those who understand: knowledge growth in teaching. Educational Researcher, 15 (4), 4-14.

Shulman, L. S. (1987). Knowledge and teaching of the new reform. Harvard Educational Review, 57, $1-22$.

Talanquer, V. (2004). Formación docente: Qué conocimiento distingue a los buenos maestros de química? Revista Educación Química, 15, (1), 60-66.

Vergnaud, G. (1990). La théorie des champs conceptuels. Reserches en Didactique des Mathématiques, $23,133-170$.

Vergnaud, G. (2009). The Theory of Conceptual Fields. Human Development, 52, (2), 83-94.

Vergnaud, G. (1996). Algunas ideas fundamentales de piaget en torno de la didactica. Perspectivas, 26 (1), 195-207. 
Marcelo G. NASCIMENTO, Marco Antonio BUENO FILHO. Analysing experienced organic chemistry teachers' teaching plans and task performances based on the theory of conceptual fields

PROBLEMS

OF EDUCATION

IN THE $21^{\text {st }}$ CENTURY

Volume 67,2015

94

Vergnaud, G. (1998). A comprehensive theory of representation for mathematics education. Journal of Mathematical Behavior, 17 (2), 167-181.

Wisconsin Center for Educational Research. (2011). Transana: Qualitative analysis software for video and audio data. Madison, WI: Author. Retrieved from http://www.transana.org/.

Advised by Rodrigo L.O.R Cunha, Federal University of ABC, São Paulo, Brazil

Received: September 30, 2015

Accepted: October 26, 2015

Marcelo G. Nascimento André, Brazil.

E-mail: marcelo.gouveia@ufabc.edu.br

Website: http://pesquisa.ufabc.edu.br/pecq

Marco Antonio Bueno Filho
PhD, Professor, Federal University of ABC, Avenida dos Estados, 5001, Santo André, Brazil.

E-mail: marco.antonio@ufabc.edu.br Website: http://pesquisa.ufabc.edu.br/pecq 